\title{
Bacteriotherapy for inflammatory bowel disease
}

\author{
Yusuke Yoshimatsu, Yohei Mikami and Takanori Kanai iD
}

\begin{abstract}
The number of patients with inflammatory bowel disease is rapidly increasing in developed countries. The main cause of this increase is thought not to be genetic, but secondary to rapidly modernized environmental change. Changes in the environment have been detrimental to enteric probiotics useful for fermentation, inducing an increase in pathobionts that survive by means other than fermentation. This dysregulated microbiota composition, the so-called dysbiosis, is believed to have increased the incidence of inflammatory bowel disease. Bacteriotherapy, a treatment that prophylactically and therapeutically corrects the composition of disturbed intestinal microbiota, is a promising recent development. In fact, fecal microbiome transplantation for recurrent Clostridioides difficile infection in 2013 was a significant contribution for bacteriotherapy. In this paper, we comprehensively review bacteriotherapy in an easy-to-understand format.
\end{abstract}

Keywords: Dysbiosis, Clostridioides (Clostridium) difficile infection, Fecal microbiome transplantation, Prebiotics, Probiotics, Bacteriotherapy

\section{Highlights}

- Dysbiosis is considered as one of the major causes of intestinal diseases and beyond.

- FMT is an alternative treatment option for patients with rCDI.

- Bacteriotherapies are studied for the treatment of intestinal dysbiosis.

\section{Introduction}

Humans have consistently consumed fermented food for a long time. Fermenters, types of bacteria known as "probiotics," allowed the invention of fermented food. It is thought that fermented foods were initially developed as a means of protecting food from corruption, but not for the purpose of health maintenance, disease prevention, or treatment. In 1911, the Russian immunologist Metchnikoff advocated probiotics' agelessness theory that health could be enhanced and senility delayed by manipulating the intestinal

\footnotetext{
* Correspondence: takagast@z2.keio.jp

Division of Gastroenterology and Hepatology, Department of Internal

Medicine, Keio University School of Medicine, 35 Shinanomachi, Shinjuku-ku, Tokyo 160-8582, Japan
}

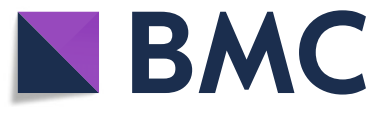

(c) The Author(s). 2021 Open Access This article is licensed under a Creative Commons Attribution 4.0 International License, which permits use, sharing, adaptation, distribution and reproduction in any medium or format, as long as you give

appropriate credit to the original author(s) and the source, provide a link to the Creative Commons licence, and indicate if changes were made. The images or other third party material in this article are included in the article's Creative Commons licence, unless indicated otherwise in a credit line to the material. If material is not included in the article's Creative Commons licence and your intended use is not permitted by statutory regulation or exceeds the permitted use, you will need to obtain permission directly from the copyright holder. To view a copy of this licence, visit http://creativecommons.org/licenses/by/4.0/. microbiome with host-friendly bacteria found in yogurt because Bulgarians who consumed large amounts of yogurt had long life spans [1]. Fermentation was a prototypical example of the symbiotic relationship between humans and the gut microbiome, further forming a beneficial intestinal environment, including barrier function and immunity [2-7]. However, these symbiotic ties have gradually grown weaker since the invention of the antibiotic penicillin. Additionally, humans invented what was considered a "magical box" at the time, the refrigerator. The refrigerator enabled longer food preservation without any complex preparation and subsequently reduced the consumption of fermented food. Decreased fermented food intake was linked to decreased intake of dietary fibers, while concurrently, the intake of animal fat and protein gained popularity in developed countries.

Over the last several decades, there has been a health boom in developed countries, and consumption of fermented foods, such as yogurt, has again grown in popularity. However, there is insufficient evidence to prove the beneficial effects of "health foods" including prebiotic or probiotic foods. Prebiotics are a rich source of fibers and natural sugars and harbor beneficial bacteria 
in the gut; as such, most of them are categorized as health foods, but not medicines [8, 9]. However, recurrent Clostridioides (formerly Clostridium) difficile infection (rCDI) which is resistant to antibiotics emerged as a serious threat to public health in the late twentieth century in Europe and the USA. Given the therapeutic success of fecal microbiome transplantation (FMT) in treating rCDI, bacteriotherapy is a hot topic among researchers and clinicians worldwide [10].

\section{Microbiota}

Humans are in symbiosis with the microbiota in the GI tract, with over 100 trillion microbiota, including 1000 types and 1 million associated genes [11]. Technological innovations in genetic analysis have shown that failure of the human-enteric symbiosis ecosystem, the so-called dysbiosis, is closely related to growing disease groups, including inflammatory bowel disease (IBD) in developed countries (Fig. 1) [12-14]. Although microbiota can be as simple as parasites that cling to nutrition from human host or "friendly" bacteria that colonize the gut to assist fermentation, the Westernized lifestyle has made harboring these "good" bacteria in the intestine more difficult. This lifestyle refers to inappropriate use of antibiotics [15], cesarean section [16], artificial milk [17], improved hygiene [18], high-fat and low-fiber diet [19], and stress [20], which all can cause dysbiosis. In particular, dietary fiber is an important nutrient for these probiotic bacteria [21], and the lack of dietary fiber intake in modern society is considered the primary cause of dysbiosis in the gut.

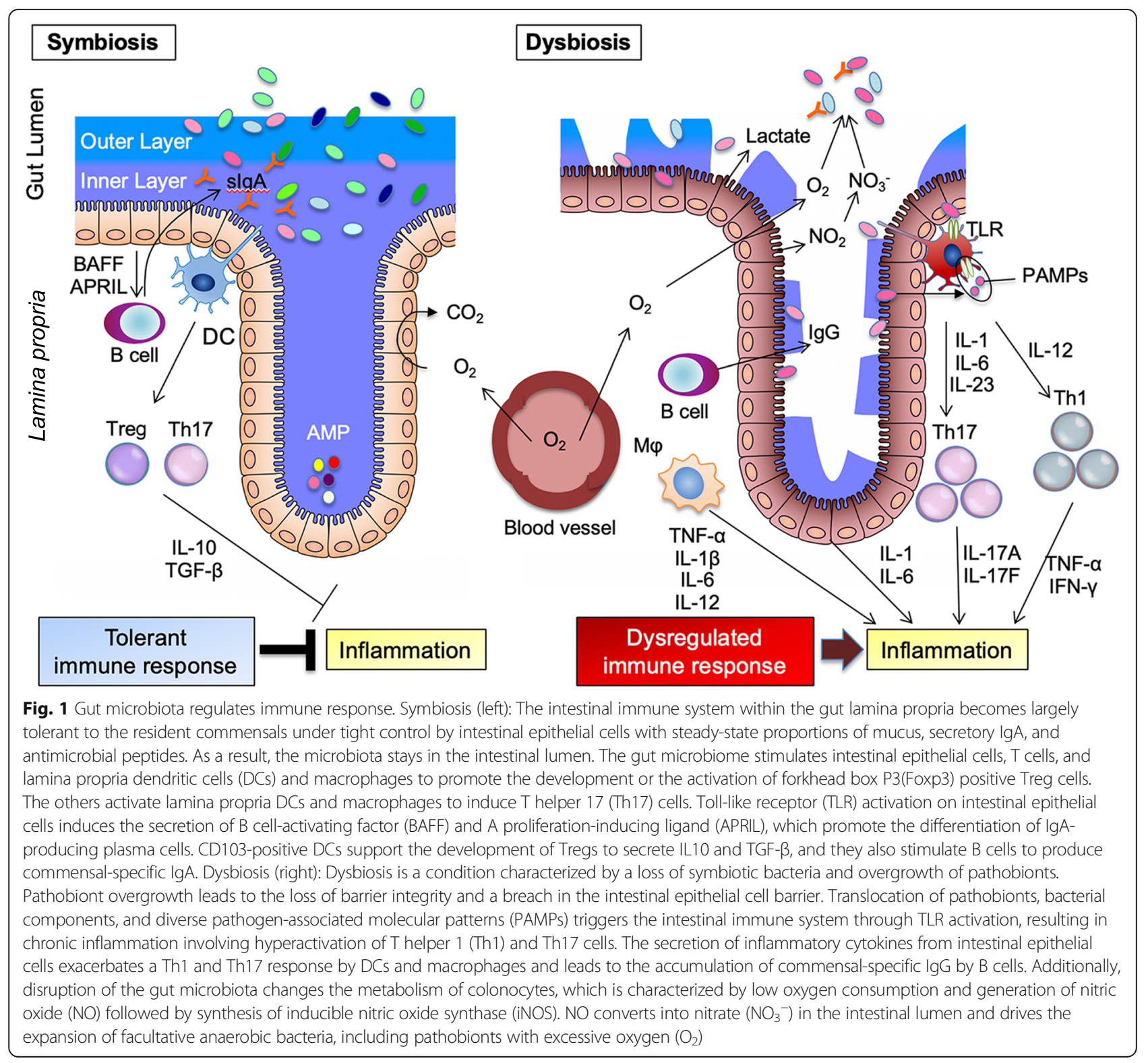




\section{Microbiota in IBD}

Many previous studies have shown environmental factors, such as modern lifestyle, diet, and antibiotic use, are associated with the development of IBD [5, 22-25]. Particularly, microbiota plays critical roles in pathogenesis of IBD together with genetic background and immunological factors. Utilizing the next-generation sequencing (NGS) technology, recent studies have profiled gut microbiota at high resolution and indicated reduced diversity of the gut microbiota in IBD patients [26-30]. For example, Frank et al. [31] demonstrated that the abundances of bacterial members of the phyla Firmicutes and Bacteroidetes are reduced and those of Actinobacteria and Proteobacteria are increased in IBD. In addition, Sokol et al. [32, 33] demonstrated that the phylum Firmicutes, and particularly a member of Clostridium cluster IV, Faecalibacterium prausnitzii, is reduced in the feces of Crohn's disease patients. Consistently, later landmark studies have revealed 17 strains within clusters IV, XIVa, and XVIII of Clostridia induces regulatory $\mathrm{T}$ cells (Tregs) in the gut $[34,35]$. Contrary to the immunosuppressive roles of specific bacteria, no specific bacteria has not been proved to do harm with IBD patients. For example, Mycobacterium avium ssp. paratuberculosis has long been suspected to have a pathogenic effect on Crohn's disease in a manner analogous to granuloma-forming mycobacterium infectious diseases [36]. However, an antitubercular drug administered to Crohn's disease patients revealed no efficacy in a 2-year clinical trial [37]. Then, the relationship between other bacterial genera, such as Listeria and Mycoplasma, and Crohn's disease has been investigated [38, 39]. However, recent studies have revealed possible interaction of "pathogenic" bacteria and breaking down intestinal homeostasis. Adherentinvasive Escherichia coli (AIEC) has been isolated from ileal biopsy samples from patients with Crohn's disease. AIEC can be pathogenic by adhering and invading intestinal epithelial cells [40, 41]. AIEC also can replicate in macrophages and stimulate production of tumor necrosis factor (TNF)-a by macrophages [41]. Fusobacterium varium has been known to attach to inflamed mucosa and invade ulcerated mucosa in ulcerative colitis patients [42]. Besides focusing on these specific microorganisms, alteration in the composition of gut microbiota has been also highlighted regarding with the pathogenesis of IBD or predication of disease course. $F$. prausnitzii is associated with the increased risk of postoperative recurrence in $\mathrm{CD}$ patients [33]. We recently demonstrated that 5-ASA intolerance is associated with a risk of adverse clinical outcomes and dysbiosis [43]. It is of note that computational analyses of gut microbiome allow to predict the efficacy of a certain biologic agent on UC [44].

In summary, the gut homeostasis is maintained by the balanced diverse microbiota and the possible "good" bacteria including members of clostridia, while some specific bacteria might be associated with developing IBD. However, it remains controversial whether the IBD-associated dysbiosis in the gut microbiota is a cause or a consequence of intestinal inflammation.

\section{Prebiotics}

Dietary fibers, unlike starches, are carbohydrates with complex sugar chain structures. In recent years, the importance of dietary fiber has been noted, but humans themselves do not possess digestive enzymes that process dietary fibers. Dietary fiber can be digested in the body by probiotics that carry digestive enzymes, and individual dietary fiber molecules are collectively called prebiotics. Thus, prebiotics are important nutrient sources for probiotics growth. Probiotics not only proliferate using prebiotics as a nutrient source, but also produce beneficial metabolites, such as short-chain fatty acids (SCFA) - propionate, acetate, butylate-that play an important role in maintaining homeostasis of the host while metabolizing prebiotics [45]. In modern society, where the intake of dietary fibers is insufficient, treatment with supplementing prebiotics is a strategy to increase probiotics, and many attempts have been made for various diseases [46-50]. At present, although there is a large amount of evidence in animal models [51-55], clinical trials have been unsatisfactory. It is possible that in these studies, the doses were too small, the dosing period was too short, or the scale of the clinical trial was too small. Healthy individuals are exposed to health information now more than ever, such as the negative effects of a diet lacking in vegetables. However, some of this information, such as fashionable promotion of organic vegetables, is not fully supported by current scientific studies.

\section{Probiotics}

Probiotics produce metabolites that are crucial for gut homeostasis. Examples of probiotic foods include yogurt, kimchi, and cheeses. With the recent boom in health information, some people have increased their intake, but this intake is likely much smaller than that of 100 years ago. We speculate that the emergence of the refrigerator-the "great invention" that changed the modern lifestyle-is critically involved in the dysbiosis in Western people. Until the eighteenth century, human beings consumed a large amount of fermented food, because fermenting was one of the major ways to preserve food, similar to salting, spicing, and smoking. Therefore, the ancient human was constantly exposed to fermenting bacteria by ingesting fermented food. However, the invention of the refrigerator enabled humans to preserve food easily, and the time-consuming process of fermented food was less common than it was in the "pre-refrigeration era." At present, as with prebiotics, there is a 
large amount of evidence in animal models [33, 35, 56-58] (Fig. 2) on the benefits of probiotics, but little evidence in clinical trials for human disease. Additionally, studies on intake of probiotics without prebiotics is likely counterproductive; fortunately, in recent years, both probiotic and prebiotic treatments (symbiotics) have been tried. Kimchi, a type of Chinese cabbage (prebiotics), and lactic acid bacteria (probiotics) are examples of symbiotics [59]. Though often forgotten, it is important to note that in probiotic foods (such as yogurt) sold today in health stores, isolated bacteria are present, rather than human-derived bacteria. Gordon et al. demonstrated that mouse gut bacteria, rather than human-derived bacteria, termite-derived bacteria, and soil-derived bacteria, have the best colonization efficiency for the murine intestinal tract [60]. Naturally, probiotics derived from human feces are expected to be the most compatible with human gastrointestinal tracts and have a noticeable therapeutic effect in treatment strategies related to human health and diseases. Unfortunately, humanderived feces are not easily adapted for patients because of a general perception of uncleanliness.
FMT

FMT has recently attracted attention in the medical field. FMT is a method of transplanting the microbiota in the feces of a healthy donor into the intestines of sick patients. FMT has a surprisingly long history and was described in China in the fourth century. In Chinese medical books, treatments with administration of feces from healthy donors to cure food poisoning are described. In 1958, one surgeon named Eisman performed FMT on four patients with pseudomembranous enteritis in the USA [61]. However, with the discovery and clinical application of various antibiotics (starting with penicillin), FMT was forgotten and only sporadically mentioned in the medical community. In the 1990s, Clostridioides difficile 027/BI/NAP1 mutant strains, which produced high levels of toxin $\mathrm{A}$, resisted antibiotics, and infections often became recurrent and fatal. Numerous cases broke out in North America and became a serious social problem. In 2013, a Dutch group reported the overwhelming efficacy of the first randomized controlled trial (RCT) for recurrent $\mathrm{CD}$ infection (CDI) [10].

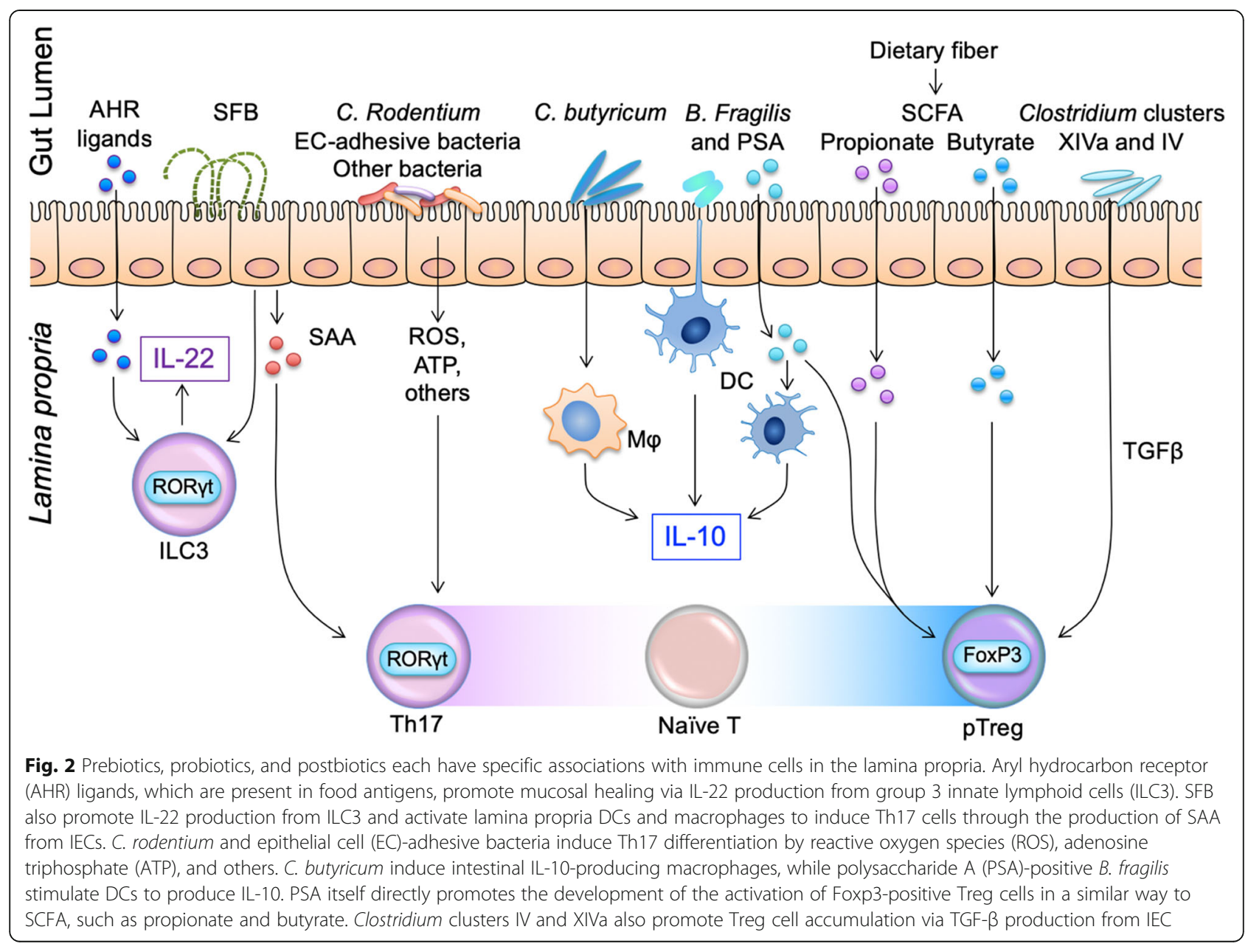


FMT is a direct example of clinically applied bacteriotherapy and became popular with the spread of microbiota analysis using next-generation sequencing technology called 16S rRNA sequencing. Numerous RCTs have proven FMT efficacy against rCDI, and meta-analysis also demonstrated their effectiveness $[62,63]$. In 2016, the Food and Drug Administration (FDA) has approved the use of FMT after rigorous informed consent and the approval of the ethical review board at the given healthcare facility. In North America, there is a drive to encapsulate feces, and promising results have been obtained treating $\mathrm{rCDI}$ with orally administered fecal capsules [64]. Fecal capsules promote the spread of FMT, but it is unclear whether processed capsules qualify under the Investigational New Drug (IND) application.

A German group, in contrast, took a unique therapeutic approach with five rCDI patients. First, third-party donorderived bacteria were suspended in saline, filtered to prevent the passage of bacteria, and administered as a nonbacterial supernatant to the patient (fecal filtrate transfer; FFT). Surprisingly, in all 5 patients, FFT restored normal stool habits and eliminated symptoms of CDI, suggesting that there is no need for conventional FMT-but, the supernatant contained a critical healing factor other than bacteria in donor feces [65]. It is possible that the critical curing factor was a metabolite or bacteriophage produced by microbiota derived from healthy donors. At present, FMT is being tested for various diseases associated with dysbiosis [66-74]. As for efficacy, in particular, it remains controversial whether FMT has a beneficial effect on active UC or not. An Australian group demonstrated that intensive-dosing ( 5 days per week for 8 weeks), multi-donor (between three and seven unrelated donors) FMT induces clinical remission and endoscopic improvement in active UC [66]. To the contrary, our group demonstrated that single FMT using feces derived from single-donor of each patients' relative has a limited effect on UC in Japanese patients [74]. This discrepancy may occur due to difficulty in restoring bacterial flora by single administration. On the other hand, as for safety, the establishment of FMT must reiterate the safety of donor feces, the mechanism of the symbiotic ecosystem between microbiota and human host, the metabolites produced by microbiota, and the other microorganisms, such as bacteriophages and fungi, coexisting in the feces.

\section{Defined microbiota}

The long-term safety of donor feces for use during FMT is still unclear. Just because the donor is a healthy person, one cannot conclude that the donor feces do not have unknown infectious agents. A Canadian group is mass-cultivating anaerobic probiotics from the feces of healthy donors using "Robogut," a robot that mimics the conditions in the colon; the group has developed a highvolume probiotics suspension composed of 33 types of bacteria [75]. It has already been reported that the bacterial cocktail shows positive effects in rCDI patients, although the trial is small [76]. These researchers used a precise process to prevent the contamination of pathogens, as with yogurt. While the safety concerns in FMT, defined microbiota, which uses probiotics from processed feces for therapeutic purposes, is treated as a drug; it therefore must be strictly studied under clinical development regulations and with an Investigational New Drug (IND) application. In 2016, the FDA revised guidelines for bacterial therapy for pharmaceutical purposes, which were different from conventional treatment with healthy food such as yogurt.

\section{Postbiotics}

With the rapid accumulation of information on genes (metagenomics) and metabolites (metabolomics) related to microbiota, researchers are attempting to apply the metabolite produced by microbiota itself. This process is called "postbiotics," and research has been actively promoted in recent years. Other examples of postbiotics include molecules that modify metabolite production. For example, a molecule that inhibits an enzyme that produces trimethylamine $\mathrm{N}$-oxide (TMAO), which promotes arteriosclerosis, is being researched as a postbiotic [77]. While these approaches are in the early stages, pharmaceutical research is rapidly growing.

\section{Probiotics and gut immunity}

It is known that the gut microbiome has a close relationship with immune cells in the lamina propria and substantially contributes to intestinal diseases [2, 4, 6, 12, 14, 78-80]. Each probiotic bacterial strain shapes unique characteristics of the immune response (Fig. 2). In one mouse model, segmented filamentous bacteria (SFB) IL-17A produce Th17 cells through the production of serum amyloid A (SAA) from intestinal epithelial cells (IEC) [81]. Some microbiota belonging to the genus Clostridium induce regulatory $\mathrm{T}$ cells (Treg) by producing butyrate from dietary fiber, and in turn, the butyrate suppresses inflammatory cytokines via mucin and antimicrobial peptide from IEC [4, 34, 35, 82, 83]. Consistently, another butyrate-producing Clostridium strain, Clostridium butyricum MIYAIRI 588, suppresses colitis via IL-10 production from intestinal macrophages and TGFbeta from dendritic cells $[5,56]$. These findings are consistent with those of recent human studies. The fecal butyrate levels and the proportion of Clostridia are significantly lower in patients with ulcerative colitis (UC) than in healthy controls [31, 84, 85]. We recently reported the efficacy of herbal medicine, indigo naturalis, in patients with active UC, which is accompanied by corrected gut microbiota [29]. We 
speculate that therapeutic agents currently used in the clinic partially, but significantly, promote "beneficial" microbiota.

\section{Conclusion}

In the near future, the mechanisms of symbiosis in various microorganisms that coexist in the intestinal environment, including intestinal microbiota, will be clarified. Future medical practice may use bacteriotherapy, which is independent of a fecal bank and applies more refined microbiota. Additionally, molecules produced by microbiota genes may appear as pharmaceuticals. At present, it is desirable to use bacteriotherapy for a group of life-threatening diseases, such as rCDI. However, for patients with non-fatal and intractable diseases, the bacteriotherapy could be challenged because lack of its safety evidence. A future of bacteriotherapy that is in harmony with the development of various drugs is desired.

\section{Abbreviations}

AHR: Aryl hydrocarbon receptor; APRIL: A proliferation inducing ligand: ATP: Adenosine triphosphate; BAFF: B cell-activation factor; DCs: Dendritic cells; EC: Epithelial cells; FDA: Food and Drug Administration; FMT: Fecal microbiome transplantation; Foxp3: Forkhead box P3; IBD: Inflammatory bowel disease; IEC: Intestinal epithelial cells; IEC: Intestinal epithelial cells; ILC3: Group 3 innate lymphoid cells; IND: Investigational New Drug; iNOS: Inducible nitric oxide synthase; $\mathrm{NO}$ : Nitric oxide; $\mathrm{NO}_{3}{ }^{-}$: Nitrate; $\mathrm{O}_{2}$ : Oxygen; PAMPs: Pathogen-associated molecular patterns;

PSA: Polysaccharide A; rCDI: Recurrent Clostridioides (formerly Clostridium) difficile infection; RCT: Randomized controlled trial; ROS: Reactive oxygen species; Th1: T helper 1; Th17: T helper 17; TLR: Toll-like receptor; TMAO: Trimethylamine N-oxide; Treg: Regulatory T cells; SAA: Serum amyloid A; SCFA: Short-chain fatty acids; SFB: Segmented filamentous bacteria; UC: Ulcerative colitis

\section{Acknowledgements}

Not applicable.

\section{Authors' contributions}

YY, YM, and TK equally contributed to this work. The authors read and approved the final manuscript.

\section{Authors' information}

YY is a board-certified internal medicine physician and gastroenterologist. He has graduated from Keio University School of Medicine and received M.D., followed by completing residency in internal medicine and in gastroenterology and hepatology. He is currently a Ph.D. student in the IBD research fellow program under supervision of Dr. Takanori Kanai at Keio University. He is interested in the unknown pathogenic mechanism of IBD and trying to develop novel treatment strategies against IBD. Now, he is working on a project that deciphers complex immune networks in intestinal mucosal immunity and elucidates mechanisms how the Chinese herbal medicine shows therapeutic effects on patients with ulcerative colitis. He wishes to develop safe and effective $\mathrm{IBD}$ treatments.

YM completed graduate school and residency training in internal medicine and in gastroenterology and hepatology at Keio University School of Medicine, in Tokyo, Japan. He studied mucosal immunology in inflammatory bowel diseases during his Ph.D. work in the laboratory of Drs. Toshifumi Hibi and Takanori Kanai. He received his postdoctoral training in the laboratory of Dr. John O'Shea at the National Institute of Arthritis and Musculoskeletal and Skin Diseases (NIAMS/NIH), studying genomic and epigenomic mechanisms that regulate innate and adaptive immunity and inflammation. His research goal is understanding unappreciated molecular mechanisms that regulate homeostasis, inflammation, wound healing, and fibrosis in the intestine, as well as identifying new therapeutic approaches for inflammatory bowel diseases.
TK completed his MD and PhD at Keio Univerisity. He is currently a Professor and Chairman of medicine, Department of Internal Medicine, Division of Gastroenterology and Hepatology. His group aims to find new insights and therapeutic approaches in autoinflammatory and cancerous diseases in digestive organs, including inflammatory bowel diseases, colorectal cancer, and primary sclerosing cholangitis. The remaining question in this field is how the host perceives the gut local environment and send appropriate metabolic and immunological feedback to the systemic organs. To achieve this goal, he particularly focuses his research on understanding neuroimmune interaction and host-microbe interaction that influences autoinflammatory diseases in the gut and beyond.

\section{Funding}

This study was supported by the Japan Society for the Promotion of Science (JSPS) KAKENHI Grant-in-Aid (B) 20H03666, (A) $15 \mathrm{H} 02534$ and 20H00536; Advanced Research and Development Programs for Medical Innovation (AMED-CREST; 16gm1010003h0001 and 20gm1210001h0002); the Takeda Science Foundation; the Kanae Foundation for The Promotion of Medical Science; Mishima Kaiun Memorial Foundation; Keio University Academic Development Funds for Individual Research; and Keio University Medical Fund. We thank Katrina Krogh, MD, from Edanz Group for editing a draft of this manuscript.

Availability of data and materials

Not applicable.

Ethics approval and consent to participate

Not applicable.

Consent for publication

Not applicable.

\section{Competing interests}

The authors declare that they have no competing interests.

Received: 10 December 2019 Accepted: 21 December 2020

Published online: 13 January 2021

\section{References}

1. Metchnikoff E. The prolongation of life. Optimistic Studies. New York: G P Putnam's Sons; 1910. p. 96.

2. Hagihara $Y$, Yoshimatsu $Y$, Mikami $Y$, et al. Epigenetic regulation of T helper cells and intestinal pathogenicity. Semin Immunopathol. 2019;41:379-99.

3. Hisamatsu T, Kanai T, Mikami Y, et al. Immune aspects of the pathogenesis of inflammatory bowel disease. Pharmacol Ther. 2013;137:283-97.

4. Honda K, Littman DR. The microbiota in adaptive immune homeostasis and disease. Nature. 2016:535:75-84.

5. Kanai T, Mikami Y, Hayashi A. A breakthrough in probiotics: Clostridium butyricum regulates gut homeostasis and anti-inflammatory response in inflammatory bowel disease. J Gastroenterol. 2015;50:928-39.

6. Mikami $Y$, Takada $Y$, Hagihara $Y$, et al. Innate lymphoid cells in organ fibrosis. Cytokine Growth Factor Rev. 2018:42:27-36.

7. Teratani T, Mikami Y, Nakamoto N, et al. The liver-brain-gut neural arc maintains the T(reg) cell niche in the gut. Nature. 2020;585:591-6.

8. David LA, Maurice CF, Carmody RN, et al. Diet rapidly and reproducibly alters the human gut microbiome. Nature. 2014;505:559-63.

9. Gibson GR, Hutkins R, Sanders ME, et al. Expert consensus document: The International Scientific Association for Probiotics and Prebiotics (ISAPP) consensus statement on the definition and scope of prebiotics. Nat Rev Gastroenterol Hepatol. 2017;14:491-502.

10. van Nood E, Vrieze A, Nieuwdorp $M$, et al. Duodenal infusion of donor feces for recurrent Clostridium difficile. N Engl J Med. 2013:368:407-15.

11. Almeida A, Mitchell AL, Boland M, et al. A new genomic blueprint of the human gut microbiota. Nature. 2019;568:499-504.

12. Kamada N, Seo SU, Chen GY, et al. Role of the gut microbiota in immunity and inflammatory disease. Nat Rev Immunol. 2013;13:321-35.

13. Brown EM, Kenny DJ, Xavier RJ. Gut microbiota regulation of T cells during inflammation and autoimmunity. Annu Rev Immunol. 2019;37:599-624.

14. Belkaid $Y$, Hand TW. Role of the microbiota in immunity and inflammation. Cell. 2014;157:121-41. 
15. Shaw SY, Blanchard JF, Bernstein CN. Association between the use of antibiotics in the first year of life and pediatric inflammatory bowel disease. Am J Gastroenterol. 2010;105:2687-92.

16. Biasucci $G$, Benenati $B$, Morelli $L$, et al. Cesarean delivery may affect the early biodiversity of intestinal bacteria. J Nutr. 2008;138:1796s-800s.

17. Penders J, Thijs C, Vink C, et al. Factors influencing the composition of the intestinal microbiota in early infancy. Pediatrics. 2006;118:511-21.

18. Bach JF. The hygiene hypothesis in autoimmunity: the role of pathogens and commensals. Nat Rev Immunol. 2018;18:105-20.

19. Chapman-Kiddell CA, Davies PS, Gillen L, et al. Role of diet in the development of inflammatory bowel disease. Inflamm Bowel Dis. 2010;16:137-51.

20. Gao X, Cao Q, Cheng Y, et al. Chronic stress promotes colitis by disturbing the gut microbiota and triggering immune system response. Proc Natl Acad Sci U S A. 2018;115:E2960-e2969.

21. Makki K, Deehan EC, Walter J, et al. The impact of dietary fiber on gut microbiota in host health and disease. Cell Host Microbe. 2018;23:705-15.

22. Sheehan D, Moran C, Shanahan F. The microbiota in inflammatory bowel disease. J Gastroenterol. 2015;50:495-507.

23. Podolsky DK. Inflammatory bowel disease (1). N Engl J Med. 1991;325:928-37.

24. Goldsmith JR, Sartor RB. The role of diet on intestinal microbiota metabolism: downstream impacts on host immune function and health, and therapeutic implications. J Gastroenterol. 2014;49:785-98.

25. Aden K, Rehman A, Waschina S, et al. Metabolic functions of gut microbes associate with efficacy of tumor necrosis factor antagonists in patients with inflammatory bowel diseases. Gastroenterology. 2019;157:1279-1292.e11.

26. Lloyd-Price J, Arze C, Ananthakrishnan AN, et al. Multi-omics of the gut microbial ecosystem in inflammatory bowel diseases. Nature. 2019:569:655-62.

27. Vich Vila A, Imhann F, Collij V, et al. Gut microbiota composition and functional changes in inflammatory bowel disease and irritable bowel syndrome. Sci Transl Med. 2018;10(472):eaap8914. https://doi.org/10.1126/ scitranslmed.aap8914.

28. Pittayanon R, Lau JT, Leontiadis Gl, et al. Differences in gut microbiota in patients with vs without inflammatory bowel diseases: a systematic review. Gastroenterology. 2020;158:930-946.e1.

29. Naganuma M, Sugimoto S, Mitsuyama K, et al. Efficacy of indigo naturalis in a multicenter randomized controlled trial of patients with ulcerative colitis. Gastroenterology. 2018;154:935-47.

30. Dalal SR, Chang EB. The microbial basis of inflammatory bowel diseases. J Clin Invest. 2014;124:4190-6.

31. Frank DN, St Amand AL, Feldman RA, et al. Molecular-phylogenetic characterization of microbial community imbalances in human inflammatory bowel diseases. Proc Natl Acad Sci U S A. 2007;104:13780-5.

32. Sokol H, Lay C, Seksik P, et al. Analysis of bacterial bowel communities of IBD patients: what has it revealed? Inflamm Bowel Dis. 2008;14:858-67.

33. Sokol H, Pigneur B, Watterlot $L$, et al. Faecalibacterium prausnitzii is an antiinflammatory commensal bacterium identified by gut microbiota analysis of Crohn disease patients. Proc Natl Acad Sci U S A. 2008;105:16731-6.

34. Atarashi K, Tanoue T, Oshima K, et al. Treg induction by a rationally selected mixture of Clostridia strains from the human microbiota. Nature. 2013;500:232-6.

35. Atarashi K, Tanoue T, Shima T, et al. Induction of colonic regulatory T cells by indigenous Clostridium species. Science. 2011;331:337-41.

36. Feller M, Huwiler K, Stephan R, et al. Mycobacterium avium subspecies paratuberculosis and Crohn's disease: a systematic review and meta-analysis. Lancet Infect Dis. 2007:7:607-13.

37. Selby W, Pavli P, Crotty B, et al. Two-year combination antibiotic therapy with clarithromycin, rifabutin, and clofazimine for Crohn's disease. Gastroenterology. 2007;132:2313-9.

38. Chen W, Li D, Paulus B, et al. Detection of Listeria monocytogenes by polymerase chain reaction in intestinal mucosal biopsies from patients with inflammatory bowel disease and controls. J Gastroenterol Hepatol. 2000;15:1145-50.

39. Ontanilla Clavijo G, Trigo Salado C, Leo Carnerero E, et al. Listeria monocytogenes and its relationship with non-biological therapy in inflammatory bowel disease. Gastroenterol Hepatol. 2015;38:442-3.

40. Atarashi $\mathrm{K}$, Tanoue $\mathrm{T}$, Ando $\mathrm{M}$, et al. Th17 cell induction by adhesion of microbes to intestinal epithelial cells. Cell. 2015;163:367-80.

41. Rolhion N, Darfeuille-Michaud A. Adherent-invasive Escherichia coli in inflammatory bowel disease. Inflamm Bowel Dis. 2007:13:1277-83.

42. Ohkusa T, Sato N, Ogihara T, et al. Fusobacterium varium localized in the colonic mucosa of patients with ulcerative colitis stimulates species-specific antibody. J Gastroenterol Hepatol. 2002;17:849-53.
43. Mizuno S, Ono K, Mikami Y, et al. 5-Aminosalicylic acid intolerance is associated with a risk of adverse clinical outcomes and dysbiosis in patients with ulcerative colitis. Intest Res. 2020;18:69-78.

44. Ananthakrishnan AN, Luo C, Yajnik V, et al. Gut microbiome function predicts response to anti-integrin biologic therapy in inflammatory bowel diseases. Cell Host Microbe. 2017:21:603-610.e3.

45. Smith PM, Howitt MR, Panikov N, et al. The microbial metabolites, shortchain fatty acids, regulate colonic Treg cell homeostasis. Science. 2013;341: 569-73.

46. Simpson HC, Simpson RW, Lousley S, et al. A high carbohydrate leguminous fibre diet improves all aspects of diabetic control. Lancet. 1981;1:1-5.

47. Ludwig DS, Pereira MA, Kroenke $\mathrm{CH}$, et al. Dietary fiber, weight gain, and cardiovascular disease risk factors in young adults. Jama. 1999;282:1539-46.

48. Liu S, Buring JE, Sesso HD, et al. A prospective study of dietary fiber intake and risk of cardiovascular disease among women. J Am Coll Cardiol. 2002 39:49-56.

49. Nilsson AC, Johansson-Boll EV, Bjorck IM. Increased gut hormones and insulin sensitivity index following a 3-d intervention with a barley kernelbased product: a randomised cross-over study in healthy middle-aged subjects. Br J Nutr. 2015;114:899-907.

50. Nicolucci AC, Hume MP, Martinez I, et al. Prebiotics reduce body fat and alter intestinal microbiota in children who are overweight or with obesity. Gastroenterology. 2017;153:711-22.

51. Llewellyn SR, Britton GJ, Contijoch EJ, et al. Interactions between diet and the intestinal microbiota alter intestinal permeability and colitis severity in mice. Gastroenterology. 2018;154:1037-1046.e2.

52. Macia L, Tan J, Vieira AT, et al. Metabolite-sensing receptors GPR43 and GPR109A facilitate dietary fibre-induced gut homeostasis through regulation of the inflammasome. Nat Commun. 2015;6:6734.

53. Trompette A, Gollwitzer ES, Yadava K, et al. Gut microbiota metabolism of dietary fiber influences allergic airway disease and hematopoiesis. Nat Med. 2014;20:159-66.

54. Cani PD, Bibiloni R, Knauf C, et al. Changes in gut microbiota control metabolic endotoxemia-induced inflammation in high-fat diet-induced obesity and diabetes in mice. Diabetes. 2008;57:1470-81.

55. Turnbaugh PJ, Ley RE, Mahowald MA, et al. An obesity-associated gut microbiome with increased capacity for energy harvest. Nature. 2006;444: 1027-31.

56. Hayashi A, Sato T, Kamada N, et al. A single strain of Clostridium butyricum induces intestinal IL-10-producing macrophages to suppress acute experimental colitis in mice. Cell Host Microbe. 2013;13:711-22.

57. Geuking MB, Cahenzli J, Lawson MA, et al. Intestinal bacterial colonization induces mutualistic regulatory T cell responses. Immunity. 2011;34:794-806.

58. Waidmann M, Bechtold O, Frick JS, et al. Bacteroides vulgatus protects against Escherichia coli-induced colitis in gnotobiotic interleukin-2-deficient mice. Gastroenterology. 2003;125:162-77.

59. Jung JY, Lee $\mathrm{SH}$, Jin HM, et al. Metatranscriptomic analysis of lactic acid bacterial gene expression during kimchi fermentation. Int J Food Microbiol. 2013:163:171-9.

60. Seedorf H, Griffin NW, Ridaura VK, et al. Bacteria from diverse habitats colonize and compete in the mouse gut. Cell. 2014;159:253-66.

61. Eiseman B, Silen W, Bascom GS, et al. Fecal enema as an adjunct in the treatment of pseudomembranous enterocolitis. Surgery. 1958:44:854-9.

62. Khan MY, Dirweesh A, Khurshid T, et al. Comparing fecal microbiota transplantation to standard-of-care treatment for recurrent Clostridium difficile infection: a systematic review and meta-analysis. Eur J Gastroenterol Hepatol. 2018;30:1309-17.

63. Hui W, Li T, Liu W, et al. Fecal microbiota transplantation for treatment of recurrent $C$. difficile infection: an updated randomized controlled trial metaanalysis. PLoS One. 2019;14:e0210016.

64. Youngster I, Russell GH, Pindar C, et al. Oral, capsulized, frozen fecal microbiota transplantation for relapsing Clostridium difficile infection. Jama. 2014;312:1772-8.

65. Ott SJ, Waetzig GH, Rehman A, et al. Efficacy of sterile fecal filtrate transfer for treating patients with clostridium difficile infection. Gastroenterology. 2017:152:799-811.e7.

66. Paramsothy S, Kamm MA, Kaakoush NO, et al. Multidonor intensive faecal microbiota transplantation for active ulcerative colitis: a randomised placebo-controlled trial. Lancet. 2017;389:1218-28.

67. Kurokawa S, Kishimoto T, Mizuno $S$, et al. The effect of fecal microbiota transplantation on psychiatric symptoms among patients with irritable 
bowel syndrome, functional diarrhea and functional constipation: an openlabel observational study. J Affect Disord. 2018;235:506-12.

68. Vrieze A, Van Nood E, Holleman F, et al. Transfer of intestinal microbiota from lean donors increases insulin sensitivity in individuals with metabolic syndrome. Gastroenterology. 2012;143:913-6.e7.

69. Xu MQ, Cao HL, Wang WQ, et al. Fecal microbiota transplantation broadening its application beyond intestinal disorders. World J Gastroenterol. 2015;21:102-11.

70. Crum-Cianflone NF, Sullivan E, Ballon-Landa G. Fecal microbiota transplantation and successful resolution of multidrug-resistant-organism colonization. J Clin Microbiol. 2015;53:1986-9.

71. McClave SA, Patel J, Bhutiani N. Should fecal microbial transplantation be used in the ICU? Curr Opin Crit Care. 2018;24:105-11.

72. Gopalakrishnan V, Spencer CN, Nezi L, et al. Gut microbiome modulates response to anti-PD-1 immunotherapy in melanoma patients. Science. 2018; 359:97-103.

73. Routy B, Le Chatelier E, Derosa L, et al. Gut microbiome influences efficacy of PD-1-based immunotherapy against epithelial tumors. Science. 2018;359:91-7.

74. Mizuno S, Nanki K, Matsuoka K, et al. Single fecal microbiota transplantation failed to change intestinal microbiota and had limited effectiveness against ulcerative colitis in Japanese patients. Intest Res. 2017:15:68-74.

75. Carlucci C, Jones CS, Oliphant K, et al. Effects of defined gut microbial ecosystem components on virulence determinants of Clostridioides difficile. Sci Rep. 2019;9:885.

76. Petrof EO, Gloor GB, Vanner SJ, et al. Stool substitute transplant therapy for the eradication of Clostridium difficile infection: 'RePOOPulating' the gut. Microbiome. 2013;1:3.

77. Chen ML, Yi L, Zhang Y, et al. Resveratrol attenuates trimethylamine-N-oxide (TMAO)-induced atherosclerosis by regulating TMAO synthesis and bile acid metabolism via remodeling of the gut microbiota. MBio. 2016;7:e02210-5.

78. Backhed F, Ley RE, Sonnenburg JL, et al. Host-bacterial mutualism in the human intestine. Science. 2005:307:1915-20.

79. Huttenhower C, Kostic AD, Xavier RJ. Inflammatory bowel disease as a model for translating the microbiome. Immunity. 2014;40:843-54.

80. Peloquin JM, Goel G, Villablanca EJ, et al. Mechanisms of pediatric inflammatory bowel disease. Annu Rev Immunol. 2016;34:31-64.

81. Ivanov II, Atarashi K, Manel N, et al. Induction of intestinal Th17 cells by segmented filamentous bacteria. Cell. 2009;139:485-98.

82. Mazmanian SK, Round JL, Kasper DL. A microbial symbiosis factor prevents intestinal inflammatory disease. Nature. 2008:453:620-5.

83. Furusawa Y, Obata Y, Fukuda S, et al. Commensal microbe-derived butyrate induces the differentiation of colonic regulatory T cells. Nature. 2013;504: 446-50

84. Takaishi H, Matsuki T, Nakazawa A, et al. Imbalance in intestinal microflora constitution could be involved in the pathogenesis of inflammatory bowel disease. Int J Med Microbiol. 2008;298:463-72.

85. Takeshita K, Mizuno S, Mikami Y, et al. A single species of clostridium subcluster XIVa decreased in ulcerative colitis patients. Inflamm Bowel Dis. 2016;22:2802-10.

\section{Publisher's Note}

Springer Nature remains neutral with regard to jurisdictional claims in published maps and institutional affiliations.

Ready to submit your research? Choose BMC and benefit from:
- fast, convenient online submission
- thorough peer review by experienced researchers in your field
- rapid publication on acceptance
- support for research data, including large and complex data types
- gold Open Access which fosters wider collaboration and increased citations
- maximum visibility for your research: over 100M website views per year
At BMC, research is always in progress.
Learn more biomedcentral.com/submissions

